\title{
Review
}

Neonatology

\section{Neonatal Thrombocytopenia and Platelet Transfusion - A UK Perspective}

\author{
Robert Carr ${ }^{a}$ Anne M. Kelly ${ }^{b}$ Lorna M. Williamson ${ }^{c}$ \\ ${ }^{a}$ Department of Haematology, Guy's and St Thomas' Hospital, King's College London, London, bepartment of \\ Haematology and Division of Transfusion Medicine, University of Cambridge, Cambridge, and ' NHS Blood and \\ Transplant, Watford, UK
}

\section{Key Words}

Infant · Newborn · Platelet transfusion - Thrombocytopenia

\begin{abstract}
Five percent of newborn infants admitted to UK neonatal units during a recent study developed a platelet count $<60$ $\times 10^{9} / \mathrm{l}$, and $60 \%$ of these were transfused platelets. This review summarises the common causes and mechanisms of thrombocytopenia in the newborn. Relevant evidence relating the platelet count to the risk of haemorrhage is reviewed, and current UK guidance on transfusion thresholds outlined. The UK policy for the provision of platelets for transfusion to neonates is described, including the particular requirements for neonatal allo-immune thrombocytopenia. Finally, we look towards the future and prospects for reducing the need to expose newborns to donor-derived platelets.
\end{abstract}

(C) 2014 S. Karger AG, Basel

\section{Normal Ranges}

Platelet production in the fetus begins around 5 weeks after conception and by the end of the second trimester has established the normal postnatal range of 150-450 $\times$ $10^{9} / 1$. However, data from the 1980 s recorded that 22 $35 \%$ of babies admitted to neonatal intensive care devel- oped thrombocytopenia below this range, rising to $70 \%$ of babies $<1,000 \mathrm{~g}$ in the current era [1]. Reference ranges derived from a large population of babies having blood counts in hospital show a lower (5th centile) limit of 105 $\times 10^{9} / 1$ for those born $\leq 32$ weeks of gestation and $125 \times$ $10^{9} / 1$ for those $>32$ weeks of gestation [2]. Postnatally, infants born at 28 weeks or earlier persist with a lower platelet count than those more mature at birth, which is likely to reflect their postnatal clinical course as well as reduced marrow reserve. This population study also revealed that all but the most immature infants have a postnatal increase in platelet count between 2 and 4 weeks after birth, with counts at the end of the 1st postnatal month frequently above $450 \times 10^{9} / 1$ [2].

\section{Etiology and Mechanisms}

Newborn infants may become thrombocytopenic during foetal life and so present with low platelets at birth, develop thrombocytopenia during the first 3 postnatal days, 'early-onset' or, at any time after this, 'late-onset' thrombocytopenia.

Presented at the International Symposium 'VIIth Recent Advances in Neonatal Medicine', Würzburg, 2014.

\section{KARGER 125}

2014 S. Karger AG, Basel

$1661-7800 / 14 / 1071-0001 \$ 39.50 / 0$

E-Mail karger@karger.com

www.karger.com/neo
Robert Carr

Department of Haematology, Guy's Hospital

King's College London

London SE1 9RT (UK)

E-Mail robtcarr@gmail.com 
Fetal acquired thrombocytopenia is most commonly due to intra-uterine infection, either viral or bacterial. It is more rarely immune mediated by maternal allo-antibodies causing neonatal allo-immune thrombocytopenia (NAIT) or maternal auto-antibodies (immune thrombocytopenic purpura, ITP). An experienced haematologist can often provide a rapid indication of whether the thrombocytopenia is due to infection by inspecting the blood film. Congenital viral infection is associated with circulating lymphocytes with a typical 'activated' morphological appearance. Chorioamnionitis is associated with an increased granulocyte count with many myelocytes and meta-myelocytes.

Early-onset thrombocytopenia is most frequently associated with chronic intra-uterine hypoxia, a consequence of placental insufficiency or acute perinatal hypoxia (perinatal asphyxia); less frequently, early-onset thrombocytopenia is due to perinatal infection. The blood count and peripheral blood film can point to the cause, particularly in perinatal asphyxia where the acute hypoxic drive mobilises large numbers of nucleated red cells into the peripheral circulation. The increase in nucleated red cells does not persist, unlike in haemolytic conditions.

Thrombocytopenia is common in small-for-gestational-age (SGA) infants and follows a pattern, with a nadir around day 4 and recovery to normal numbers by the end of the 1st week [3]. The mechanism appears to be that the chronic hypoxia of placental insufficiency drives haematopoiesis towards increasing red cells with a reciprocal reduction in platelet and, commonly, neutrophil production [4]. In vitro studies show megakaryocytes and their precursors to be reduced in number with high blood levels of thrombopoietin, which fall as platelet numbers increase $[4,5]$. Clinically, this early thrombocytopenia, which is associated with intra-uterine growth restriction, pregnancy-induced hypertension or diabetes, is present or develops soon after birth, rarely falls below $50 \times 10^{9} / 1$ and resolves over 7-10 days. This evolution is well demonstrated by sequential counts from a cohort of SGA infants in the control arm of a prophylactic GM-CSF study (PROGRAMS; fig. 1) [6].

Late-onset thrombocytopenia is in most cases caused by systemic bacterial sepsis or necrotising enterocolitis (NEC). The mechanism is platelet consumption mediated by associated disseminated intravascular coagulation and probably exacerbated by poor marrow reserve [7]. In the PROGRAMS cohort of 280 SGA infants, there were 86 episodes of blood culture-positive sepsis, $55 \%$ of which were associated with an acute fall in the platelet count to $<50 \times 10^{9} / 1$ at the time of onset. Perhaps surprisingly, this

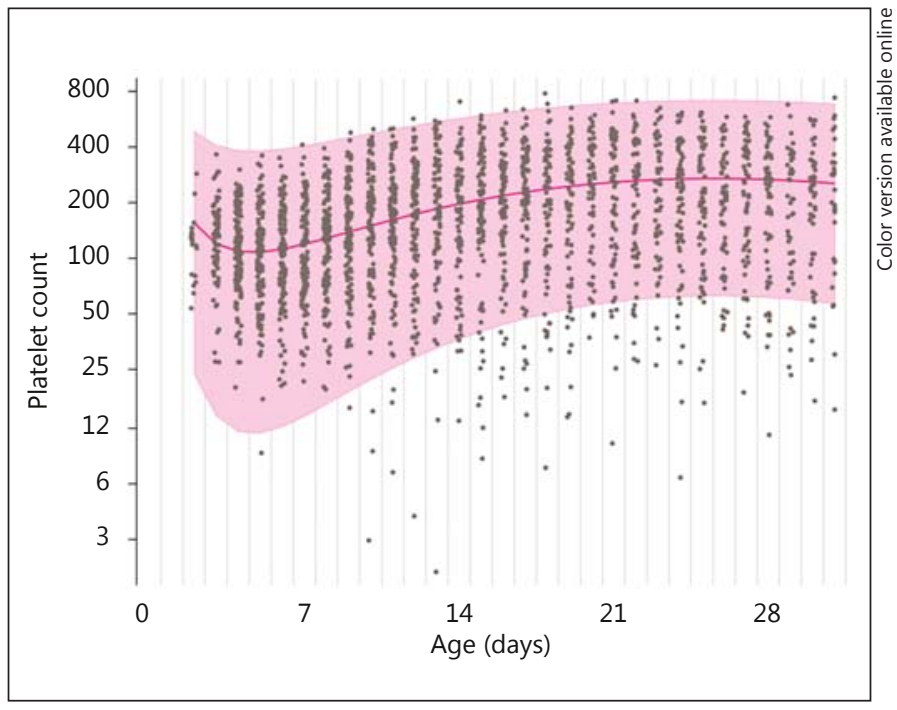

Fig. 1. Sequential daily platelet counts from a cohort of 141 SGA preterm infants $\leq 32$ weeks of gestational age during the 1st postnatal month. $\mathrm{x}$-axis $=$ Post-natal age in days; $\mathrm{y}$-axis = logarithmic platelet count. The median and normal (95\%) range is shown.

septicaemia-associated thrombocytopenia was as common in coagulase-negative staphylococcal sepsis as in episodes where Gram-negative or other pathogenic bacteria were cultured ( 60 vs. $45 \%$ of episodes, respectively).

\section{Indication for Platelet Transfusion}

The greatest users of platelets are adults with leukaemia undergoing chemotherapy or stem cell transplantation. The accepted prophylactic platelet transfusion threshold in this setting is a platelet count of $\leq 10 \times 10^{9} / 1$, but after 3 decades of clinical experience and study, the evidence for a benefit of prophylactic platelets even at this threshold is conflicting $[8,9]$. In neonatal practice, there is less evidence, and opinions on appropriate platelet transfusion thresholds differ on each side of the Atlantic, with prophylactic transfusion being instituted at higher platelet thresholds in the USA and Canada compared to European practice $[10,11]$.

The greatest concern in the preterm infant is to prevent periventricular haemorrhage. This was addressed by Maureen Andrew 2 decades ago in a multicentre randomised controlled trial of preterm infants with mild thrombocytopenia $\left(50-150 \times 10^{9} / 1\right)$ randomised to receive, or not, prophylactic platelets to maintain the count above $150 \times 10^{9} / 1$ for 7 days. In 152 infants, the incidence 
Table 1. Platelet transfusion guidelines for newborn infants in the UK

\begin{tabular}{|c|c|c|c|}
\hline $\begin{array}{l}\text { Platelet } \\
\text { threshold } \times 10^{9} / 1\end{array}$ & $\begin{array}{l}\text { First postnatal week } \\
\text { No clinical haemorrhage }\end{array}$ & $\begin{array}{l}\text { After first postnatal week } \\
\text { No clinical haemorrhage }\end{array}$ & $\begin{array}{l}\text { Any age } \\
\text { Major clinical haemorrhage }\end{array}$ \\
\hline$<30^{\mathrm{a}}$ & Transfuse all infants & Transfuse all infants & Transfuse \\
\hline$<50$ & $\begin{array}{l}\text { Transfuse, if any of: } \\
\text { Birth weight }<1,000 \mathrm{~g} \\
\text { Clinically unstable } \\
\text { Suspected sepsis } \\
\text { Abnormal coagulation } \\
\text { Previous haemorrhage } \\
\text { Exchange transfusion }\end{array}$ & $\begin{array}{l}\text { Do not routinely transfuse } \\
\text { except when there are } \\
\text { co-existing risk factors, e.g. NEC }\end{array}$ & Transfuse \\
\hline$>50 \times 10^{9} / 1$ & Do not transfuse & Do not transfuse & Transfuse \\
\hline
\end{tabular}

of periventricular haemorrhage was equivalent between the randomised arms (28 vs. $26 \%$ in controls) [12], a finding confirmed by others [13].

Taking into account that platelets in newborns may be less haemostatic [reviewed in ref. 14], and that both adults and neonates in intensive care are at greater clinical risk of bleeding as a consequence of interventions and clinical instability, the British Committee for Standards in Haematology advised, in 2004, a prophylactic platelet threshold for stable preterm and term infants of $20 \times 10^{9} / 1$ and of $30 \times 10^{9} / 1$ for sick neonates [15]. However, it was recognised that there was little evidence to show whether a liberal or more restrictive platelet transfusion strategy influenced the outcome of severe thrombocytopenia. To provide a more evidence-based approach, an observational study was undertaken to examine existing UK practice. Infants admitted to 7 UK neonatal units over a period of 1 year were recruited, with parental consent, if their platelet count fell below $60 \times 10^{9} / 1$ [16]. Five percent of all admitted infants to participating neonatal units developed platelets $<60 \times 10^{9} / 1 ; 50 \%$ were associated with sepsis or NEC and $25 \%$ with intra-uterine growth restriction or pregnancy-induced hypertension; a third of cases had a nadir count below $20 \times 10^{9} / 1$. The study did not define a transfusion threshold and platelets were transfused at local clinician discretion. The study found that most platelet transfusions were given during the 1st postnatal week; the majority ( $81 \%$ ) were given as prophylaxis for a count below the transfusion threshold of the individual unit, $16 \%$ because of factors perceived to increase the risk of haemorrhage and only $3 \%$ as treatment for haemorrhage.

Thrombocytopenia and Platelet Transfusion
The study findings relevant to informing future practice were: (i) a third of all study infants developed thrombocytopenia $<20 \times 10^{9} / 1$, but these infants constituted the minority of cases with minor or major bleeding episodes, and only 1 in 10 had bleeding classed as severe; (ii) the strongest predictors for all haemorrhage were birth $<34$ weeks of gestation, a platelet count $<50 \times 10^{9} / 1$ within 10 days of birth or acute systemic infection, and (iii) the strongest predictor for major haemorrhage was early thrombocytopenia after birth at less than 28 weeks or NEC in any infant $[16,17]$.

In the absence of any randomised trial testing prophylactic platelet transfusion thresholds for newborn infants, current UK advice is based on expert opinion. The recommendation is that prophylactic platelets be given to all neonates, term or preterm, with a confirmed platelet count $<20 \times 10^{9} / 1$, to stable preterm infants if the count falls below $30 \times 10^{9} / 1$ and to all with a birth weight of $<1,000 \mathrm{~g}$ if the platelets are $<50 \times 10^{9} / 1$ during the 1 st week. A threshold of $50 \times 10^{9} / 1$ is commonly used for infants who are clinically unstable, have had a previous major bleed or have other recognised risk factors [18] (table 1).

To develop a more evidence-based approach, the previous observational study has been succeeded by a UK multicentre randomised trial to explore two different thresholds for prophylactic platelet transfusion $[19,20]$. Neonates are recruited if their platelet count falls below $50 \times 10^{9} / 1$, and randomised to receive platelet transfusions if the count on any day is below one of two thresholds: $50 \times 10^{9} / 1$ or $25 \times 10^{9} / 1$. The primary outcomes are major bleeding episodes or death from any cause within 
28 days from trial entry. To date, over 200 infants have been recruited to the trial, about one third of the target sample size.

An interesting alternative approach developed by Christensen et al. [21], within the Intermountain Healthcare Service (Utah, USA), has been the concept of 'platelet mass' as a guide for transfusion decisions, where platelet mass is the product of peripheral blood platelet count and mean platelet volume, routinely quantitated by automated counters. A change in prophylactic transfusion policy from that based on platelet count to the compound platelet mass index resulted in fewer platelet transfusions without compromising clinical outcomes [22, 23].

\section{Immune Thrombocytopenias (NAIT/ITP)}

Thrombocytopenia in the fetus or newborn may result from platelet auto-antibodies in the mother with ITP or systemic lupus erythematosus, or platelet allo-antibodies against paternal platelet antigens inherited by the fetus, NAIT. In the former, it is the mother that is at risk of haemorrhage during delivery, in the latter the mother's platelets are normal, but the fetus is at risk of life-threatening haemorrhage in utero and after birth.

\section{Autoimmune Thrombocytopenia}

In mothers with ITP, there is only a $10 \%$ risk of their infant being thrombocytopenic, with no more than a $1 \%$ risk of in utero intracranial haemorrhage [24]. The risk of neonatal thrombocytopenia appears greater for mothers with more severe thrombocytopenia during pregnancy $[25,26]$. All infants with a maternal history of ITP/systemic lupus erythematosus should have an early postnatal platelet count, and if below the normal range this should be monitored, as the platelet count may fall during the first 3-5 postnatal days before recovering spontaneously. If the platelets persist below $30 \times 10^{9} / \mathrm{l}$, intravenous immunoglobulin usually corrects the thrombocytopenia [27].

\section{Neonatal Allo-Immune Thrombocytopenia}

NAIT is a rare condition (approx. 1 in 1,000-1,500 neonates) which occurs when the mother lacks a common platelet antigen that the fetus has inherited paternally. The condition is thus the platelet equivalent to haemolytic disease of the newborn. The most frequently involved human platelet antigen (HPA) is HPA-1a, for which $2.5 \%$ of Caucasians are negative, followed by HPA$5 \mathrm{~b}$ and other then less common antigens, such as those in the HPA-15 system. HPA-1a antibody formation is strongly associated with maternal carriage of the HLADRB3 $* 101$ gene, which has a frequency of $32 \%$ in a largely Caucasian UK population [28]. If maternal IgG develops, this is able to cross the placenta and cause thrombocytopenia in the fetus.

Unlike haemolytic disease of the newborn, very few screening programmes are in place. A further difference from haemolytic disease of the newborn is that NAIT can occur in a first pregnancy in about $50 \%$ of cases, possibly because of shedding of antigen from the placenta (which is of foetal origin) into the maternal circulation. Thus, major or even fatal haemorrhage can arise in utero in a first pregnancy. The diagnosis should be considered in any otherwise well neonate presenting at birth with unexplained petechiae or purpura/other haemorrhage and severe thrombocytopenia $<50 \times 10^{9} / 1$. The most severe consequence is intracranial haemorrhage, both in utero and postnatally, so cerebral ultrasound should be performed whilst the diagnosis is investigated. Diagnosis needs to be undertaken by a specialist platelet immunology laboratory. In the UK, this is provided by the National Blood Transfusion Services. Samples from neonate and mother are essential; a sample from the father is helpful, but initial investigation should not be delayed if this is not immediately available. The maternal sample is screened for platelet allo-antibodies, beginning with a rapid screening for anti-HPA-1a. Confirmation will require more extensive serology using panels of platelet antigens, along with platelet antigen typing of mother and neonate. In the UK, typing at the DNA level (genotyping) has largely replaced earlier methods.

Treatment should be with appropriately typed and matched platelets. In the UK, the National Blood Transfusion Services keeps a stock of HPA-1a- and HPA-5bnegative platelets on the shelf, which can be issued while investigations are ongoing. Neonatal units should be aware of what their blood supplier can provide. If typed platelets are not immediately available, random donor platelets should be given to keep the count $>50 \times 10^{9} / 1$, with the aim of preventing postnatal intracranial haemorrhage. A platelet count $1 \mathrm{~h}$ after administration will inform how effective random platelets are at raising the count. The addition of intravenous immunoglobulin ( $1 \mathrm{~g} / \mathrm{kg} /$ day for 1-3 days) may help reduce platelet destruction and maintain an adequate count [29-31]. The thrombocytopenia usually resolves in $8-10$ days but rarely may persist for up to 12 weeks.

When platelets lacking the relevant antigen cannot be provided and there are poor responses to random platelets, compatible platelets can be obtained from the moth- 
er by apheresis. However, this is not a trivial undertaking, and there are two important caveats: (i) the platelets must be washed to remove maternal plasma and re-suspended in saline or $A B$ plasma. Infusion of maternal antibody with the platelets can exacerbate and prolong the infant's thrombocytopenia, and (ii) the platelets must be gammairra-diated to prevent graft-versus-host disease from viable maternal lymphocytes that may be in the platelet concentrate.

Subsequent pregnancies can be managed with intravenous immunoglobulin and/or intra-uterine platelet transfusions, and need close co-operation between obstetricians, haematologists and neonatologists [32]. For the future, a recent proof-of-principle study has shown that a recombinant anti-HPA-1 antibody can, in vivo, block platelet destruction by immune HPA-1 IgG antibodies [33].

\section{Platelets for Transfusion to Infants in the Neonatal Intensive Care Unit}

In the UK, all platelets for neonates are produced by means of apheresis from a single donor. Each donation is split into small-volume paediatric packs of $50-75 \mathrm{ml}$, which are reserved for a single infant to limit donor exposure. Neonatal platelet donations are screened to ensure that each pack contains $>40 \times 10^{9}$ platelets and $<2.5 \times 10^{5}$ leucocytes, and group $\mathrm{O}$ units are screened to exclude those with high-titre anti-A or anti-B (table 2). Recently bacterial screening has been introduced, permitting extending storage (at $22^{\circ} \mathrm{C}$ on an agitator) from 5 to 7 days.

Since 1999, in the UK, all blood components have been depleted of leucocytes to reduce the risk of transmission of variant Creutzfeldt-Jakob disease. While leucodepletion also reduces the risk of transmission of cytomegalovirus (CMV) and engraftment of donor lymphocytes (the cause of graft-versus-host disease), small numbers of lymphocytes remain. During the first 28 days after birth, neonates are given cellular blood components only from $\mathrm{CMV}$-screened and -negative donors. Irradiated platelet units are required for infants at specific risk of developing transfusion-associated graft-versus-host disease. These include those with congenital cardiac disease (who may have underlying $\mathrm{T}$ cell immunodeficiency), known immunodeficiency and babies who have received an intrauterine transfusion [34].

The standard protocol for neonate platelet transfusion is $\mathrm{ABO} /$ rhesus-matched or compatible, and infused at $10-20 \mathrm{ml} / \mathrm{kg}$. The PlaNet (Platelets for Neonatal Transfu-
Table 2. Platelets for neonatal transfusion in the UK (adapted from the Guidelines for the Blood Transfusion Services in the UK 2013: www.transfusionguidelines.org)

\begin{tabular}{|c|c|}
\hline $\begin{array}{l}\text { Donor } \\
\text { assessment }\end{array}$ & $\begin{array}{l}\text { General medical history } \\
\text { Risk factors for transfusion-transmitted } \\
\text { infections } \\
\text { Risk factors for variant Creutzfeldt-Jakob } \\
\text { disease, e.g. pituitary hormone therapy, corneal } \\
\text { grafts, blood transfusion since } 1980 \\
\text { Haemoglobin above UK thresholds (women } \\
12.5 \mathrm{~g} / \mathrm{dl} \text {; men } 13.5 \mathrm{~g} / \mathrm{dl} \text { ) } \\
\text { Male donors preferred to reduce risk of } \\
\text { transfusion-related acute lung injury }\end{array}$ \\
\hline $\begin{array}{l}\text { Donation } \\
\text { testing }\end{array}$ & $\begin{array}{l}\text { Serology and genome testing for HIV, HCV, } \\
\text { HBV, HTLV } \\
\text { Serology for CMV } \\
\text { Returning travellers for West Nile virus, } \\
\text { malaria, Trypanosoma cruzi } \\
\text { Female donors tested for leucocyte antibodies } \\
\text { to reduce risk of transfusion-related acute lung } \\
\text { injury }\end{array}$ \\
\hline Specification & $\begin{array}{l}\text { All prepared from single donors, collected by } \\
\text { apheresis } \\
\text { All are routinely leucocyte depleted } \\
\text { Single apheresis donations split into paediatric } \\
\text { packs } \\
50-75 \mathrm{ml} \text { per paediatric pack } \\
>40 \times 10^{9} \text { platelets per paediatric pack } \\
\text { ABO/Rh identical or compatible } \\
\text { CMV negative for infants during first } 28 \text { days }\end{array}$ \\
\hline $\begin{array}{l}\text { Special } \\
\text { considerations } \\
\text { for NAIT }\end{array}$ & $\begin{array}{l}\text { HPA-1a and - } 5 \mathrm{~b} \text { negative and negative for } \\
\text { allo-antibody } \\
\text { Must irradiate if maternal platelets }\end{array}$ \\
\hline
\end{tabular}

sion) study showed a wide range of platelet increments with the first transfusion, almost certainly in part reflecting the variable concentration of platelets in each pack [16]. A more pragmatic approach might be to tailor the platelet transfusion to the maximum fluid volume that can be safely given over the period of $3 \mathrm{~h}$ that is considered microbiologically safe after the pack seal has been breached.

\section{Alternative Treatments for Neonatal Thrombocytopenia}

\section{Thrombopoietin Analogues}

Thrombopoietin (TPO) is the cytokine that drives platelet production in the marrow. Early clinical studies using a recombinant human TPO led to neutralising an- 
tibodies which cross reacted with endogenous TPO, leading to refractory thrombocytopenia. Since then two synthetic TPO mimetics have been licensed for use in ITP, the oral agent eltrombopag and romiplostim given parentally. Both may be effective in refractory ITP $[35,36]$.

Might these agents have a place in neonatal thrombocytopenia to reduce the use of blood products [37]? On theoretical grounds, this seems unlikely. Sepsis-associated thrombocytopenia needs urgent correction and is largely caused by increased platelet consumption, and both agents take several weeks of treatment to translate the stimulation of platelet production into increased circulating platelet numbers. The thrombocytopenia of placental insufficiency is due to reduced platelet production, but endogenous TPO levels are already high. Furthermore, the analogous precedent of using G-CSF or GMCSF to increase neutrophil production and boost marrow reserves of mature neutrophils in infants with or at risk of neutropenia did not translate into clinical benefit [38].
Platelets from Stem Cells in the Laboratory?

The prospect of unlimited supplies of platelets, without need for donors or the risks associated with blood products, engineered to avoid immune destruction and with enhanced haemostatic properties has graduated from the realms of science fiction [39]. With work ongoing in Cambridge, UK, and the USA, there are many challenges to overcome, but the boundless ingenuity of medical science suggests that future donor-independent therapeutic platelets should not be discounted. The small size and increased vulnerability of preterm infants would make them the ideal early beneficiaries.

\section{Disclosure Statement}

The authors report no conflicts of interest.

\section{References}

1 Christensen RD, Henry E, Weidmeier SE, Stoddard RA, Sola-Visner MC, Lambert DK, Kiehn TI, Ainsworth S: Thrombocytopenia among extremely low birth weight neonates: data from a multihospital healthcare system. J Perinatol 2006;26:348-353.

- 2 Wiedmeier SE, Henry E, Sola-Visner MC, Christensen RD: Platelet reference ranges for neonates, defined using data from over 47,000 patients in a multihospital healthcare system. J Perinatol 2009;29:130-136.

- 3 Castle V, Andrew M, Kelton J, Giron D, Johnston M, Carter C: Frequency and mechanism of neonatal thrombocytopenia. J Pediatr 1986;108:749-755.

4 Murray NA, Roberts IAG: Circulating megakaryocytes and their progenitors in early thrombocytopenia in preterm neonates. Pediatr Res 1996;40:112-119.

5 Watts TL, Murray NA, Roberts IAG: Thrombopoietin has a primary role in the regulation of platelet production in preterm babies. Pediatr Res 1999;28:28-32.

6 Carr R, Brocklehurst P, Dore CD, Modi N: Granulocyte-macrophage colony stimulating factor administered as prophylaxis for reduction of sepsis in extremely preterm, small for gestational age neonates (the PROGRAMS trial): a single-blind, multicentre, randomised controlled trial. Lancet 2009;373:226-233.
7 Roberts IAG, Murray NA: Neonatal thrombocytopenia: causes and management. Arch Dis Child Fetal Neonatal Ed 2003;88:F359-F364.

-8 Stanworth SJ, Estcourt LJ, Powter G, Kahan BC, Dyer C, Bakrania L, Llewelyn C, Littlewood T, Soutar R, Norfolk D, Copplestone A, Smith N, Kerr P, Jones G, Raj K, Westerman DA, Szer J, Jackson N, Bardy PG, Plews D, Lyons S, Bielby L, Wood EM, Murphy MF; TOPPS Investigators: A no-prophylaxis platelet-transfusion strategy for hematologic cancers. N Engl J Med 2013;368:1771-1780.

-9 Wandt $\mathrm{H}$, Shaefer-Eckart K, Wendelin K, Pilz B, Wilhelm M, Thalheimer M, Mahlknecht U, Ho A, Schaich M, Kramer M, Kaufmann M, Leimer L, Schwerdtfeger R, Conradi R, Dölken G, Klenner A, Hänel M, Herbst R, Junghanss C, Ehninger G; Study Alliance Leukemia: Therapeutic platelet transfusion versus routine prophylactic transfusion in patients with haematological malignancies: an openlabel, multicentre, randomised study. Lancet 2012;380:1309-1316.

10 Josephson CD, Su LL, Christensen RD, Hillyer CD, Castillejo MI, Emory MR, Lin Y, Hume H, Easley K, Poterjoy B, Sola-Visner M: Platelet transfusion practices among neonatologists in the United States and Canada: results of a survey. Pediatrics 2009;123:278-285.

11 Cremer M, Sola-Visner M, Roll S, Josephson CD, Yilmaz Z, Bührer C, Dame C: Platelet transfusions in neonates: practices in the United States vary significantly from those in Austria, Germany and Switzerland. Transfusion 2011;51:2634-2641.
12 Andrew M, Vegh P, Caco C, Kirpalani H, Jefferies A, Ohlsson A, Watts J, Saigal S, Milner $\mathrm{R}$, Wang E: A randomised controlled trial of platelet transfusions in thrombocytopenic premature infants. Pediatrics 1993;123:285291.

13 von Lindern JS, Hulzebos CV, Bos AF, Brand A, Walther FJ, Lopriore E: Thrombocytopaenia and intraventricular haemorrhage in very premature infants: a tale of two cities. Arch Dis Child Fetal Neonatal Ed 2012;97:F348F352.

14 Sola-Visner MC: Platelets in the neonatal period: developmental differences in platelet production, function, and hemostasis and the potential impact of therapies. Hematology Am Soc Hematol Educ Program 2012;2012: 506-511.

15 Gibson BE, Todd A, Roberts I, Pamphilon D, Rodeck C, Bolton-Maggs P, Burbin G, Duguid J, Boulton F, Cohen H, Smith N, McClelland DB, Rowley M, Turner G; British Committee for Standards in Haematology Transfusion Task Force: Writing group: Transfusion guidelines for neonates and older children. Br J Haematol 2004;124:433453.

16 Stanworth SJ, Clarke P, Watts T, Ballard S, Coo L, Morris T, Murphy MF, Roberts I: Prospective, observational study of outcomes in neonates with severe thrombocytopenia. Pediatrics 2009;124:e826-e834. 
17 Muthukumar P, Venkatesh V, Curley A, Kahan BC, Choo L, Ballard S, Clarke P, Watts T, Roberts I, Stanworth S: Severe thrombocytopenia and patterns of bleeding in neonates: results from a prospective observational study and implications for use of platelet transfusions. Transfus Med 2012;22:338-343.

18 Chakravorty S, Roberts I: How I manage neonatal thrombocytopenia. Br J Haematol 2011; 156:155-162.

19 PlaNeT-2: study protocol. http://www.planet-2.com/downloads/205/PlaNeT2Protocolv20.pdf.

20 Curley A, Venkatesh V, Stanworth S, Clarke P, Watts T, New H, Willoughby K, Khan R, Muthukumar P, Deary A: Platelets for neonatal transfusion - study 2: a randomized controlled trial to compare two different platelet count thresholds for prophylactic platelet transfusion to preterm neonates. Neonatology 2014;106:102-106.

21 Christensen RD, Paul DA, Sola-Visner MC, Baer VL: Improving platelet transfusion practices in the neonatal intensive care unit. Transfusion 2008;48:2281-2284

-22 Gerday E, Baeir VL, Lambert DK, Paul DA, Sola-Visner MC, Pysher TJ, Christensen RD: Testing platelet mass versus platelet count to guide platelet transfusions in the neonatal intensive care unit. Transfusion 2009;49:20342039.

23 Christensen RD, Carroll PD, Josephson CD: Evidence-based advances in transfusion practice in neonatal intensive care units. Neonatology 2014; 106: 245-253.

24 Burrows RF, Kelton JG: Low fetal risk in pregnancies associated with idiopathic thrombocytopenic purpura. Am J Obstet Gynecol 1990;163:1147-1150.
5 Valat AS, Caulier MT, Devols P, Rugeri L, Wibaut B, Vaast P, Puech F, Bauters F, Jude $B$ : Relationships between severe neonatal thrombocytopenia and maternal characteristics in pregnancies associated with autoimmune thrombocytopenia. Br J Haematol 1998;103:397-401.

26 Webert KE, Mittal R, Sigouin C, Heddle NM, Kelton JG: A retrospective 11-year analysis of obstetric patients with idiopathic thrombocytopenic purpura. Blood 2003;102:4306-4311.

27 Ballin A, Andrew M, Ling E, Perlman M, Blanchette V: High-dose intravenous gammaglobulin therapy for neonatal autoimmune thrombocytopenia. J Pediatr 1988;112: 789-792.

28 Williamson LM, Hackett G, Rennie J, Palmer CR, Maciver C, Hadfield R, Hughes D, Jobson $\mathrm{S}$, Ouwehand WH: The natural history of fetomaternal alloimmunization to the plateletspecific antigen HPA-1a (PlA1, Zwa) as determined by antenatal screening. Blood 1998;92: 2280-2287.

29 Bussel J: Diagnosis and management of the fetus and neonate with alloimmune thrombocytopenia. J Thromb Haemost 2009;17(suppl 1):253-257.

30 Ghevaert C, Campbell K, Walton J, Smith GA, Allen D, Williamson LM, Ouwehand $\mathrm{WH}$, Ranasinghe E: Management and outcome of 200 cases of fetomaternal alloimmune thrombocytopenia. Transfusion 2007;47:901-910.

31 Peterson JA, McFarland JG, Curtis BR, Aster RH: Neonatal alloimmune thrombocytopenia: pathogenesis, diagnosis and management. Br J Haematol 2013;161:3-14.

32 Salomon O, Rosenberg N: Predicting risk severity and response of fetal neonatal alloimmune thrombocytopenia. $\mathrm{Br} \mathrm{J}$ Haematol 2013;162:304-312.
33 Ghevaert C, Herbert N, Hawkins L, Grehan N, Cookson P, Garner SF, Crisp-Hihn A, Lloyd-Evans P, Evans A, Balan K, Ouwehand WH, Armour KL, Clark MR, Williamson LM: Recombinant HPA-1a antibody therapy for treatment of fetomaternal alloimmune thrombocytopenia: proof of principle in human volunteers. Blood 2013;122:313-320.

34 Treleaven J, Gennery A, Marsh J, Norfolk D, Page L, Parker A, Saran F, Thurston J, Webb D: Guidelines on the use of irradiated blood components prepared by the British Committee for Standards in Haematology blood transfusion task force. Br J Haematol 2011; 152:35-51.

35 Journeycake JM: Childhood immune thrombocytopenia: role of rituximab, recombinant thrombopoietin, and other new therapeutics. Hematology Am Soc Hematol Educ Program 2012;2012:444-449.

36 Arnold DM: Positioning new treatments in the management of immune thrombocytopenia. Pediatr Blood Cancer 2013;60(suppl 1):S119-S122.

37 Sallmon H, Gutti RK, Ferrer-Marin F, Liu ZJ, Sola-Visner MC: Increasing platelets without transfusion: is it time to introduce novel thrombopoietic agents in neonatal care? J Perinatol 2010;30:765-769.

38 Carr R: The role of colony stimulating factors and immunoglobulin in the prevention and treatment of neonatal infection. Arch Dis Child Fetal Neonatal Ed 2013;98:192-194.

- 39 Lambert MP, Sullivan SK, Fuentes R, French DL, Poncz M: Challenges and promises for the development of donor-independent platelet transfusions. Blood 2013;121:3319-3324. 